\title{
Comparing Conceptions of Social Ontology: Emergent Social Entities and/or Institutional Facts? \\ Version 03/05/2015
}

\author{
Tony Lawson ${ }^{1}$ \\ Faculty of Economics, \\ Sidgwick Avenue, \\ Cambridge CB3 9DD, UK \\ Tony.Lawson@econ.cam.ac.uk
}

It is commonplace, if erroneous, to suppose that worldviews (or ontological conceptions) that underpin, or are presupposed by, substantive analyses and/or methodological stances are somehow beyond interrogation ${ }^{2}$. This is thought to be especially so regarding social ontological orientations (see discussion in Lawson 2014). To the contrary ontological conceptions, including those relating to the social realm, are easily shown to be subject to empirical assessment in both absolute terms (see e.g. Lawson 2003 chapter 2; Lawson 2014) and in comparison to the explanatory power of competing accounts (see e.g., Lawson 2014, 2015a).

In advancing a specific theory of social ontology over the years I have often drawn support for the conception defended by contrasting it with the (largely implicit) ontology of closed systems of isolated atoms presupposed by very many social theorists -- and most especially by contemporary economists, not least in their heavy reliance on methods of mathematical modelling (see Lawson 2015a). However, it can with reason be said that in making this comparison I have been choosing a relatively soft target. This is doubtless true. But my purpose in making this comparison was not so much to garner additional explanatory support for the ontological conception I defend as to employ the clear explanatory superiority of the latter to cast doubt on the wisdom of the prevailing widespread uncritical reliance on methods of mathematical modelling in social theory (an emphasis that in modern mainstream economics yet continues unabated).

In the current paper, though, I do want to compare the conception I defend with a more serious target or alternative. It seems to me that the conception of social ontology that is most widely known and influential, at least outside of modern economics, is that associated with John Searle. As far as I know the conception advanced by Searle and that which I have long defended have hitherto not be systematically contrasted. Here I embark on an initial attempt to make a comparative evaluation. It is true that the two conceptions are frequently noted together in passing (sometimes being speculated as being similar at other times as opposed) ${ }^{3}$.

\footnotetext{
${ }^{1}$ Forthcoming in the Journal for the Theory of Social Behaviour. I am indebted to the Independent Social Research Foundation for funding the research on which this paper draws.

${ }^{2}$ Very often the phrase 'that's merely metaphysical' (where metaphysics and ontology and interpreted widely as interchangeable) is voiced in a manner that can only be interpreted to mean that the claim being referenced is mere speculation and not open to empirical assessment. This of course is an orientation encouraged by the logical positivists. As Rudolf Carnap, a leading contributor expressed matter: "Metaphysicians are musicians without musical ability" (Carnap, The Elimination of Metaphysics, in Sarkar, Sahotra (ed.), Logical Empiricism at its Peak, p. 30).

${ }^{3}$ Of course neither conception has been developed without the input of others, and I am particularly grateful to others involved on social ontology in Cambridge. Both Searle and I are involved with social ontology groups in our own universities, i.e., with the Cambridge Social Ontology Group (CSOG) and the Berkeley Social Ontology Group BSOG respectively. Both groups might be said to be developing joint projects in social ontology. For contributions to the former see for example Lawson, 1994,1997, 2003, John Latsis et al., 2007; Stephen Pratten, 2014. For contributions to the Berkeley project see especially Searle, 1995, 2010. Of course, it would be a mistake to suppose that either of the two groups are internally fully homogenous. However, I believe that in terms of broad philosophical perspective each group is relatively homogeneous compared to the contrasts across the two groups, and here in effect I shall be focusing on the latter differences by considering the conceptions of myself and Searle.
} 
But to my knowledge they have not hitherto been systematically contrasted and evaluated relative to each other ${ }^{4}$.

My finding is that in terms of formal commitments the two conceptions defended appear strongly opposed. For whilst I am committed to the reality of emergent social entities Searle is reluctant to go any further than acknowledging a reality of institutional facts. That is, while I am committed to the reality of 'social objects', Searle allows only that we can talk of different facts about any given (non-social) object (this is a piece of paper, we count this object as money), and that is all we need to form a coherent social ontology.

It will be seen that underpinning this contrast are differences in fundamentals. Whilst Searle puts his primary emphasis on language as a foundational feature of social reality, I additionally emphasise the organising role of emergent collective practices in sustaining (equally emergent) social totalities. It is this contrast that I seek primarily to examine here.

So the two conceptions are prima facie very different. However, I will be suggesting that these differences are not as incompatible as they at first appear. I will certainly be arguing for the explanatory superiority of the account I have previously defended. But where systematic contrasts in the two conceptions are identified I will be suggesting that not only do they not render the two projects are irreconcilable, but that the position I defend is seemingly frequently implicit in Searle's own reasoning, especially when he seeks to resolve issues that are found to be problematic for his conception.

\section{Preliminaries: apparent similarities}

Although I am here concerned with identifying and evaluating contrasting assessments, let me start by briefly sketching some fundamental (apparent) similarities.

Most obviously the projects have the same broad objective, if slightly different domains of primary focus.

In my own research, the focus is the social realm understood as the set of all phenomena whose existence depends necessarily ${ }^{5}$ on human beings and their interactions. The goal is to defend and explain the possibility of investigating social phenomena through providing (fallible) explanatory insights and assessments whose truth or falsity depend not on opinions of specific observers but on the way the world is (Lawson, 1997, 2012).

Searle gives primary focus to a slightly narrower set of phenomena, concentrating on those said to be "ontologically subjective in the sense that they exist only as experienced by human and animal subjects" (Searle, 2010, p. 18). But the goal is similar. Thus Searle specifically distinguishes 'epistemically objective statements' as those of which the "truth and falsity can be ascertained independently of the attitudes and opinions of observers", and questions "How can there be an epistemically objective set of statements about a reality which is ontologically subjective? (Searle, 2010, p. 18; emphasis in the original).

\footnotetext{
${ }^{4}$ Because this contrast is my focus I will necessarily have to leave aside the huge literature that has been concerned with critiquing either my own conception or that of Searle, as well as Searle's replies excepting where the latter bears on relevant issues of comparison of our two positions and represent the most developed account of Searle's thinking certain topics of contention that I can find.

${ }^{5}$ The qualifier 'necessarily' is attached to exclude those phenomena that depend contingently on us. To the extent we have the power to destroy species, and perhaps eventually to blow up (part of) the moon, then such phenomena depend for their existence on our not doing so. The qualifier 'necessarily' prevents such phenomena being thereby classified as social.
} 
Both accounts are self-consciously naturalistic in the sense of seeking to remain consistent with the most explanatorily successful accounts of non-social natural science. For Searle this is achieved more or less by design. But it has been an objective of my own account as well (see especially Lawson, 2012).

Perhaps the most striking apparent feature of similarity in the resulting accounts of the nature of society is one that I have throughout referred to as social positioning (Lawson, 1994, 1997, 2012, 2015a, 2015b, 2015c) and which Searle refers to as assigning of statuses (or of status functions) (Searle, 1995, 2010).

On my account an individual becomes (acquires the identity of) a university professor, prime minister, or taxi driver, etc., on being collectively accepted/recognised as having gained (legitimate) occupancy of the position Professor, Prime Minister, Taxi Driver, etc ${ }^{6}$.

Associated with each such position is a set of collective practices, rights and obligations. Similarly an artefact becomes (acquires the identity of) a table, cash, passport, and so on, on being collectively accepted/recognised as positioned as such. In this case certain causal features of the positioned objects in question become interpreted as their functions (see e.g. Lawson, 1994, 1997, 2003, 2012).

Seemingly in parallel Searle writes:

"The distinctive feature of human social reality [...] is that humans have the capacity to impose functions on objects and people where the objects and the people cannot perform the functions solely in virtue of their physical structure. The performance of the function requires that there be a collectively recognized status that the person or object has, and it is only in virtue of that status that the person or object can perform the function in question. Examples are pretty much everywhere: a piece of private property, the President of the United States, a twenty dollar bill, and a professor in a university are all people or objects that are able to perform certain functions in virtue of the fact that they have a collectively recognized status which enables them to perform those functions in a way they could not do without the collective recognition of the status" $(2010$, p. 7$)$

Proponents of both conceptions stress that collective acceptance or recognition does not imply necessary approval of the content of that which is recognised. Rather these terms are employed to indicate the existence of a shared belief that such and such a situation is so, and a willingness of each ('accepting') individual (for the time being) thereby to go along with that situation (see e.g., Lawson, 1997, 2012, p. 360; Searle 2010, p. 8).

A slight difference between the two conceptions is that I argue that the glue of society that holds it all together are the human capacities of being trustworthy and of trusting. These are essential if obligations are to be met, and individuals are prepared to act on the expectation of their being met. Searle instead suggests that the glue takes the form of the statuses (or status functions):

"It is because status functions carry deontic powers that they provide the glue that holds human civilization together. And how do they do that? Deontic powers have a unique trait

\footnotetext{
${ }^{6}$ I shall throughout follow the convention of capitalising the first letter of any positions but not any occupants. Thus a lecturer occupies the position Lecturer.
} 
[...]: once recognized, they provide us with reasons for acting that are independent of our inclinations and desires." (2010, p. 9)

This suggested difference does appear rather minimal, but may be found to reflect distinctions that are perhaps ultimately rather important. In any case, it is to the latter seemingly more significant differences that I now explicitly turn.

I start by outlining notions that, if accepted by Searle, figure at best only implicitly in his analysis, whereas for my own purposes, they are rendered explicit and systematic, because I regard them as fundamental. I am thinking in particular of social emergence, and in particular the community as an emergent relationally-organised, and so structured, entity or totality, where I take the community to be the locus of most of the features that the two conceptions hold in common. In maintaining this conception I am, as already noted, thus committing myself to the reality of social entities and structures, whereas Searle, again as already noted, prefers to talk of, and is seemingly reluctant to commit himself on the existence of anything beyond, social or rather 'institutional' facts.

Let me elaborate, starting by outlining my own conception of social entities and specifically emergent communities, before turning to give an overview of Searle's account of collective intentionality, status functions, status function declarations and institutional facts.

\section{A Social Entity Conception: Emergence, Community and Collective Practice}

By emergence I mean the appearance of novelty or something previously absent or unprecedented, somehow fashioned out of, if remaining dependent upon, matters already in existence. Emergent phenomena, or at least those that interest me here, are bound up with novel (emergent) totalities or systems, and specifically those that express (or can be interpreted as expressing) a form of coherence at the system level. Any such emergent totality, I have elsewhere argued, typically comes into being via a process whereby preexisting elements become (perhaps with some modification) relationally organised to constitute thereby components of a novel system. Such a process always occurs in a context, so that some of these components become also related to features of the local environment.

Any system or totality that so emerges is, qua an organised system, irreducible to the sum total of the elements that come to serve as components just because it is constituted in part by the manner in which the components are arranged or relationally organised; the relational organisation too is an emergent. As a result, ontological reduction of the emergent totality to the pre-existing elements alone, considered apart from their being relationally organised, is proscribed. For the same reason any emergent powers of efficient causation of an emergent totality are irreducible to, in the sense of being not predictable from knowledge of, the causal powers of the original elements considered apart from their eventual manner of organisation as components of the totality. So, causal reduction of a simple sort is also proscribed ${ }^{7}$ (see Lawson, 2013a).

Consider, as an illustration, the construction of a building to serve, say, as a house. The components include bricks, mortar, wood, panes of glass, cement, etc. Of course there will

\footnotetext{
${ }^{7}$ There are more sophisticated forms of the thesis of casual reduction that hold that emergent causal powers are, if not straightforwardly reducible to, nevertheless explicable solely in terms of the causal powers of the components. However, I show elsewhere that this is generally not the case, and seemingly not at all so with respect to social causation (see Lawson, 2013a).
} 
be a context, a plot of land, and this will be prepared so that the various components can relate to it in an appropriate manner. At any stage in the process of construction an observer will find not only the part of the building constructed so far, formed out of various elements serving now as components, but also the relational organisation of the latter components (to each other, and to elements in their environment). And this organisation will be essential to the house's construction and properties. As the house is completed, so is the relational organisation of the house's components; the two - the totality and the organisational structure -- emerge simultaneously. Each are causal, but in different ways. The house has the powers to provide safety and shelter, to facilitate family or other indoor activities, to be bought and sold, and so on. The arrangement of the parts makes the house feasible. The latter is a form of formal causation.

To appreciate the role of arrangement or organisation in contributing to the emergent powers of the totality, imagine the house being taken apart and the various elements that comprised its components now being bound together in a blind or random fashion. It is unlikely the outcome will have the (efficient) causal powers of a house. The organisation or arrangement of the bricks and other bits and pieces makes a difference. And on this criterion of causality, i.e., of possessing the power or ability to make a difference, the relational organisation is causal. Clearly, then, if ultimately somewhat trivially, the causal powers of the emergent totality are not predictable from those of the elements used to form its components if the latter are considered apart from the manner in which they are to be arranged.

\section{The social domain}

The example of the house already draws us into a consideration of the social domain (as I delimit the latter). The house is a form of artefact, a form of emergent social totality that is necessarily dependent on human interaction for its coming into being (and being maintained). I argue that there are essentially two general forms of emergent social entity. The more fundamental sort are, or can be termed, communities, these being forms of organised systems that include human beings amongst the components. The second kind are artefacts. These do not have humans as components; rather they mostly (especially in the case of 'high technology') are constituted through the relational organisation of other artefacts. An additional specific emergent system is language ${ }^{8}$ (on all this see Lawson, 2012, 2013a, 2013b).

According to the conception I defend, but possibly not according to Searle's, central features such as (those that I designate) positions (statuses) and associated rights, obligations and collective practices are relativized to, and indeed are in fact properties of, particular communities. By collective practices I understand those ways of proceeding (in order to achieve specific sorts of outcomes) that the community accepts as the done (as the collectively accepted) ways (at least for those appropriately positioned). It is positions, and associated positional rights, obligations and collective practices that form the structure of human systems or communities, that relationally organise the human components.

Here it is important to recognise that not only are there both rights and obligations associated with any given position (and so accessed by any occupant of the position) but also each of these rights (obligations) is matched by obligations (rights) associated with some other (thereby internally related) positions.

\footnotetext{
${ }^{8}$ Whilst entities such as corporations can be positioned as both artefacts and as communities - see below and Lawson 2015b,
} 2015c) 
Thus an individual appointed to the position University Lecturer within the UK community, and so acquiring the (positional) identity of university lecturer, is allowed to follow various practices, where being so permitted are amongst the rights of occupying the position. The content of these rights may include the use of university libraries and other research resources, of being paid by the state, etc. The individual is also not only allowed, but also required, to follow various practices; these are the obligations of being so positioned, and their content may include giving lectures, and setting and marking exams, etc. But any positional rights accessed by the individual are always matched by obligations of others. If a university lecturer has the rights to use an office, borrow from university libraries etc., these rights are matched by and to obligations of other positioned individuals or groups to ensure there are processes in place serving to fund, facilitate and maintain university offices, libraries, lecture halls, and so forth. Similarly, the obligations of lecturers to give lectures, set exams, mark them fairly, etc., are matched by student rights to attend lectures, sit exams, expect the exams to be marked, and fairly; and so on.

\section{Social relations and power}

If human individuals are organised through being positioned as components of a system, and if the various positions are interrelated by way of connecting rights and obligations, it is these connections that most qualify as the content of the category social relation. In other words, a social relation just is (or is first and foremost) an accepted set of (matching) rights and obligations holding between, and connecting, two or more positions or occupants of positions. Social interaction can be understood as the contingent actualisations of such social relations.

Moreover, because any positioned rights are matched by, and as noted are internally related to, one or more obligations of others positioned elsewhere, rights and obligations can be said to be (positive and negative) (positional) powers. There are two aspects at least to this latter assessment. First a right is a power in the sense that it is something the bearer has the ability to do but need not; a power can always exist unexercised. Thus, being positioned as a university academic at Cambridge University I have the power to work in a university office, to borrow a book from my faculty library, etc. But in all such cases I may choose never to do so. Second, where these powers exist they are always over others and their practices. Thus, certain others have the obligation to sign me out a book from my Faculty library if I request it, whether they wish to or not. Yet others have obligations to ensure my office, and indeed the library, is usable, including maintaining the IT facilities in each. Thus, if on a given day I find my computer does not work, or, say, that my office window has somehow shattered leaving glass all over my office floor, I may elect to sort everything myself as best I can, but I retain the power to get some other appropriately positioned party to sort it all for me, whether they really want to or not. So rights and obligations are indeed positive and negative powers, and so all social relations are power relations.

\section{Social entities}

A final feature I want briefly to (re)emphasise is that all these noted emergent phenomena, if mind dependent, are real; in particular the social systems that I am calling communities are real entities. Of course they depend on human beliefs and interactions and are continually being reproduced and transformed through practice; and so are in process. But then so seemingly is most of the rest of reality also processual in nature (see Lawson, 2012). 
Rights and obligations I take to be equally real. To recall, these are powers which, in content, are essentially allowed and required ways of doing things for occupants of specific positions, constituted in relation to other allowed and required ways of doing things. They rest on a shared belief that every member, or at least a relevant subset, of the community has implicitly 'agreed' or 'accepted' to bide by, or go along with, them where such 'agreement' or 'acceptance' can arise or emerge in any of a number of ways (described below). Where members of the community (fallibly) believe certain collective agreements are in place they act on these beliefs and conform to the practices implicated.

Very often rights and obligations emerge via a process of negotiation whereby formal agreement is reached and the content of the latter (regarding allowed and required ways of doing things for those appropriately positioned) is recorded in some manner, in signed documents, such as contracts and deeds of ownership, etc.

On other occasions any 'agreement' can be indirect or anyway ensuing, with declarations of positioning rights and obligations being assigned by someone or body (collectively) held/agreed to (be positioned appropriately as to) have the right or authority so to declare them. If, say, a government that is (collectively) regarded as legitimate declares a new bank holiday, and this directive is widely regarded as being within government's legitimate remit, there may well emerge within the community at large an acceptance that, on a relevant day, working people have a right to do something other than go to work. Such declarations, though, are only really constitutive if (eventually) they are validated by (through the conformity of the collective practices of) those implicated in the declaration.

Frequently, such declarative powers may rest merely on the grounds of one or more individuals being appropriately positioned regarding access to appropriate resources or connections, etc. Thus we might imagine the formation, say, of a symphony orchestra. Here one or more individuals may obtain a sponsorship, declare the existence of a specific symphony orchestra, decide the latter's positions and associated rights and obligations, advertise the positions, and seek to appoint appropriately trained individuals to the positions. The orchestra is an emergent but planned community. Individuals may join via a process of selection and by agreeing to the conditions set in terms of rights and obligations. And the initial declaration is validated (its conditions of satisfaction met) only if, first the call is deemed legitimate in the wider community, second appropriately qualified individuals sign up, and third the orchestra is eventually accepted as a functioning entity within the community.

Any performance too will be planned. When playing a particular composition each musician positioned as a component of the orchestra will have an obligation to contribute at a relevant moment as indicated by a score and perhaps a conductor, as well as an obligation to remain silent and attentive when others are playing, just as he or she has the right to expect the same of others, where the others have matching obligations to act similarly in their turn, and so on. Here the sets of positioned rights and obligation of the orchestra, provide the structure via which the various situated musicians interact to produce the output that is a symphony.

However, many of the more interesting sets of rights and obligations, or forms of behaviour that are taken to represent the content of community agreement or acceptance, do emerge in a somewhat more spontaneous manner and are manifest in the structuring of community collective practices, practices that are thereafter taken as constituting the accepted ways of 
doing things in the respective community. Collective practices effectively carry and manifest shared beliefs about implicit collective agreements about what can and should be done in a relevant context to achieve some specific (sorts of) goal(s).

Frequently, a pattern of behaviour emerges unwittingly for, say, allocating something relatively scarce, such as queuing in a particular manner or direction to obtain food at a rock concert, or to pay in a local store; and from there on in all members of the community conform in the belief that the existing pattern is that which is accepted within the community. They suppose that their right to participate is tied to an obligation to do so in the observed way.

Certain driving practices too are a familiar example of a more spontaneous emergence of sets of rights and obligations. Early morning commuters in the UK (certainly around Cambridge) quickly discover that different practices are followed than are in evidence later in the day. Those entering main roads from side roads are allowed onto the main roads at regular intervals. Very often the emergent pattern is that one car enters from the side road, then one car on the main road passes by the entrance of the side road, then another from the side road enters, then another from the main road passes, etc. Sometimes the emergent pattern is two or three from the main road pass then one from the side road enters, then two or three pass on the main road etc. Where patterns such as these and others emerge, any individual that does not conform is routinely tut-tutted, receiving of finger waving, have horns sounded at them and so on ${ }^{9}$.

The point, of course, is that if such patterns and associated practices did not emerge, then, with so much traffic around early in the morning, cars on the side roads would be jammed locked for hours. As it happens co-ordinating practices such as I describe emerge without anyone explicit direction or declaration, and for the most part are not only not covered by formal procedures of the "highway Code" but are contrary to them ${ }^{10}$. Nevertheless if any motorist wishes to be an early morning commuter in the UK, certainly near Cambridge where I live, then in order to participate competently, the individual commits to the conditions of satisfaction of participating appropriately in the motoring collective practices of the sort found on this road. And typically, each community member does seemingly seek to conform to any spontaneous form of collective practice believed to be in place. Deontology, in the

\footnotetext{
9 On a main road that leads from the outskirts of Cambridge in the south-west into the centre of the city there is a (final) roundabout. The first half mile of the section of this main road leading into the centre that comes after the roundabout takes the form of a dual carriage way; the road then narrows as a single lane. In the past, when driving into the centre of Cambridge on this road, I have regularly used the dual carriageway part of this road to overtake slower vehicles. On moving out to live in the village located in the south west, I have starting entering on this road in the morning rush hour. The first time I did so I started overtaking on the dual carriage way part of the road, as was my custom. But I noticed eventually that all the other cars kept to a slow crawl on the inner part of this dual carriage way, in a moving queue that stretched back to the roundabout and beyond; no one else, in other words, used the outer lane to overtake. When I got to the end of the dual carriage section of the road I was politely allowed into the main single lane stream. The second morning, I arrived at the dual carriage way I took the outside lane again and overtook all the other cars. But this time I looked at the faces of the drivers crawling along single file in the inner lane. All were looking at me and shaking their heads, raising eyebrows and generally sending me negative vibes. Although I was breaking no formal code, it was clear enough that I was here going against a spontaneously emergent collective practice. I received a clear message that driving slowly on the inside lane was indeed the done way of proceeding at this time of day, and that, as a community member, I was considered to be under an obligation to conform (and I have not taken the outside lane of the dual carriage way part of that road in the morning rush hour since).

${ }^{10}$ Of course, I am having to represent, almost codify, the patterns to communicate them in writing. But they emerge without codification, or any necessary symbolic representation. Nor is any pattern quite as precise as I have just represented it. But there are identifiable accepted collective practices in place all the same, and all the practices of individual members of the community become tokens of typically spontaneous community collective practices, which clearly embody or manifest in their structure various sets of rights and obligations.
} 
form of commitment etc., is internal to certain collective driving practices with each individual act of conforming constituting a form of participation in the particular community.

I am suggesting, then, that forms of collective practice frequently emerge within communities or as (sub) communities emerge, as aspects of social structure. In accepting (and being accepted) to be positioned as a member of the community, each individual makes a (usually merely implicit) commitment to conform to the accepted collective practices of the community. This cooperation is an essential feature of the coordination of the interactions of community members. As a consequence each community member is not only obliged to conform, but has a right to expect that all others will do so.

So social power relations can be highly informal and are seemingly all pervasive. I am suggesting that a deontology can spontaneously occur even where a queue forms or a particular local and informal collective driving practices emerge. Indeed, there are deontologies being drawn upon even as individuals walk down a public street in almost any community, certainly in the UK (see Lawson, 2013b). Wherever there emerges a communitywide collective practice, every member of the relevant community has a right to participate, but an obligation to do so in the manner perceived as the done way.

Thus, participants in any ongoing queue, say, who observe a set of new arrivals bypassing the queue and walking to the front of it, usually understand themselves to have the right to protest, and regularly do so. Similarly motorists observing specific individuals (possibly unwittingly) breaking informal local motoring collective practices in the UK send the sorts of vibes and signals of disapproval that usually quickly lead to the individuals recognising the relevant collective practices and conforming.

It is beliefs (about the collective acceptance by others) that condition actual (individual) practice. But there is typically a presumption that positionings and/or the determination of positional deontologies have been legitimately achieved (according to already established accepted ways of doing things).

Where collective practices have emerged spontaneously their legitimacy can typically be taken for granted just because the participants are also the instigators of the practices, wittingly or otherwise; there is no sense of having them imposed from the outside (by authority) in ways that may be illegitimate or 'fake'. In the case of formal agreements and declarations this may not be the case. Thus counterfeit money, forged works of art, mistaken decisions in sports games, innocent people erroneously sent to jail, and so on, may all function in the manner of genuine articles or correct decisions, etc., if everyone in the community, including those with the relevant powers, believe (erroneously) the articles to be genuine and/or decisions correct, etc. But if or where evidence of their illegitimacy comes to light and is generally accepted, positionings are, where feasible, often changed or even annulled. In other words, even, and perhaps especially, where formal agreements including declarations are the source of the deontology, their being collectively accepted, itself a condition of the validation of the agreements or declarations, will require (a collective belief) that it was an appropriate party that, in an appropriate manner, made any such agreements or declarations in the first place.

Of course, even the most widespread of collective practices are rarely if ever open to everyone in a given community. I do not see children diving cars on the road, and there is a presumption that the other drivers, at least in the UK, have passed some kind of driving test, 
and have been certified as doing so. In other words, there are implicit acceptances in play not only with regards to ways of going on that can and sometimes should be followed but also concerning positions and position membership. Collective practices, when restricted in accessibility, in effective manifest not just rights and obligations but positions too, an indication of the grouping or kind of member that may exercise any such ways of going on. Where the appropriate positioning of individuals cannot (as it can be with child drivers) be determined by appearance, forms of identification are typically involved (along perhaps with contracts that formalise membership of a position along with rights and obligations).

The conception I defend, then, is of a social reality that is mind-dependent but not mind determined; there is always a practical dimension. Social reality is in large part at least structured by interlocking, internally related, often spontaneously emergent collective practices, carrying, in the sense of manifesting, (often contested) rights and obligations interrelating the human beings who undertake these practices as positioned components of communities, of which the positions and practices in turn are properties. As such this social reality is in a sense both given to individual human beings at the moment each comes to act, as a (typically unacknowledged) condition of their individual (positioned) practices, and also reproduced and/or transformed as a (typically unintended) result of these individual practices taken in total.

Whether the elements of social structure emerge spontaneously or by explicit design including declaration, in all cases the structural elements are properties of an emergent community through which a coordination of individual practices is achieved by way of its positioned members or participants interacting in ways that conform to collective practices, manifesting rights and obligations associated with their community positionings.

It should be clear by now too why I take the glue of society to be the human capacities both to be trustworthy and to trust, to enter into and to keep to commitments and to accept that others are able and willing to do so as well. For it is the exercising of these capacities that ultimately binds rights to matching obligations in practice. This is a bonding that needs to hold if specific communities are to facilitate (and to be reproduced by way of facilitating) the successful coordination of all the separate individual practices or actions of its participants, each with their own particular goals and concerns.

I have run through this because I think Searle interprets, and certainly presents his take on, these sorts of issues somewhat differently. Of course, Searle must, and does, have ways of dealing with the sorts of issues raised. But in place of a discussion of social entities, and specifically of emergent communities, and of ways and means by which community members, perhaps typically though sub-communities, come to position human individuals and objects in various ways as components, as well as generate collective practices, Searle focusses on the contribution of language, invoking the categories of collective intentionality, status function declarations, and institutions as sets of rules grounding institutional facts. Let me briefly elaborate.

\section{Searle's alternative conception}

Searle's primary concern is actually a reality that he labels institutional. This in effect is a realm of status functions carrying deontologies created by speech acts taking the form of, or being logically similar to, Declarations. Let me explain this statement. 
A fundamental feature of Searle's account is his notion of collective intentionality. For Searle is it supposed from the outset that any feature of social ontology must be a creation of the mind; intentionality is just that property of the mind that creates the reality that Searle seeks to understand (2010, p. 25).

Intentionality, more specifically, is a capacity of the mind whereby mental states (caused by processes in the brain, and realised in the brain as biological phenomena) are directed at, or are about, objects, events, or situations in the world. Intentional states thus include belief, desire, hope, fear, etc.

Collective intentionally is the capacity of each individual for first person plural forms of intentionality. Here each individual in a group can be separately thinking "We are making X", "We believe such and such is so", and "We intend to do Z". Notice that this not the same as two or more people in a group either each thinking 'I intend to play music as part of a symphony', or jointly thinking 'we intend to play music as part of a symphony'; rather each member individually thinks 'we intend to play music as part of a symphony'. Searle is especially interested in collective intentions in planning and in acting.

The notion of collective intentionality has at least two basic components: the intention itself (in terms only of the outcomes an individual supposes he or she alone can achieve), and a belief about the sorts of related things certain relevant others are doing that can be taken for granted:

"In cases of collective intentionality, we have to distinguish what I can individually cause, that which can be part of the condition of satisfaction of my intentional content, and that which I take for granted as contributed by my collaborators in the collective intentionality. If we are playing in a symphony, all that I can actually cause is my individual performance. But I make that performance as my contribution to the total collective performance" (Searle, 2010, pp. 44-5).

Notice that the content of the individual's intention need not make reference to the content of the intentions of the 'collaborators' or any relevant participating others. All that the individual needs to know is that others are working in some way towards the same goal, or anyway acting in ways consistent with that goal being achieved. It is not necessary that, say, the individual knows how the others are doing it (Searle, 2010, pp. 52-55) ${ }^{11}$.

In my own account, it is worth noting, the reason that any individual can indeed take for granted, i.e., rely on, and come to believe that he or she can rely on, the actions of others is that all those involved are always acting as components of an organised emergent community, where the general function of the various organising collective practices is precisely to facilitate community coordination. Specifically, it is the notion of an emergent community that delimits the set of relevant others, along with a structure of obligations that allows beliefs to be formed that in certain circumstances others are acting consistently with an individual's own goals. In particular, it grounds a belief that the effective cooperation of certain others in a particular activity can be taken for granted. Thus in the example of a symphony orchestra, the

\footnotetext{
${ }^{11}$ Thus Searle observes, in a context where he is imagined to be engaged in a joint action with one other, "A crucial feature is worth repeating: The content of my singular intentionality [..] does not make essential reference to the content of your singular intentionality. I simply take it for granted, in that context, that if I do my part we will be trying to achieve that goal, because I am operating on the assumption that you will do your part, and you are operating on the assumption that I will do my part" (2010, p. 54).
} 
various musicians are amongst its separate components bound together by appropriate facilitating rights and obligations and collective practices, etc. Being components of a particular totality means that the various individuals qua positioned musicians actively cooperate; that is the point of the community that is the orchestra. Here each musician can with reason take it for granted, indeed trust, that he or she is playing an instrument in a context where, because of the generalised acceptance of the organising obligations etc., others are also playing their instruments in an appropriate way.

Whether or not an individual can strictly be said to cause her or his own performance, an issue on which Searle and I do both agree is that the action of the totality, here the performance of the symphony, is certainly not caused by the action of the components; rather it is constituted by their relationally organised activities. Thus focussing now on a duet Searle writes:

"[Consider] the case in which we are performing a duet where I play the piano part and you play the violin part. Here our playing does not cause the duet to be performed. My playing and your playing simply constitute the performance of the duet. So from my point of view, I have a collective intention-in-action that we play the duet by way of me playing the piano, in a context where I take in for granted that you are playing the violin (Searle, 2010 , p. 52; italics in the original)

I repeat that, at least according to my own conception, the reason Searle can take it for granted that the other person is playing the violin, the reason each person needs to know the substance only of what he or she alone is required to do, is that both are positioned as organised components of the social totality/community that is a musical ensemble where an appropriate form of cooperation is part of the positioned obligations, and each trusts the other to fulfil those obligations.

It is this organised cooperation that Searle seeks to capture with his notion of collective intentionality ${ }^{12}$. Searle even uses the phrase 'constitutive-by-way-of relation'. All that is missing, by my own thinking, is a recognition that any such relation is the property of a totality/community serving to combine various elements as the community's (thereby coordinated and cooperating) components.

\section{Declaration and assignment of function}

Instead of viewing individuals as materially/practically positioned as components of a totality, however, Searle seemingly proposes a more mentalistic or representational approach. According to it individuals rather are merely 'counted' as in effect being appropriately positioned, with associated positional powers or functions.

\footnotetext{
${ }^{12}$ Indeed Searle is insistent that in developing his notion of collective intentionality it is not enough that the individuals who are involved are doing similar things or a contributing to the same end; they have to be cooperating in their activities. Cooperation has several requirements in terms of belief, but the latter alone are not sufficient. Actually, Searle at one point suggests that nevertheless cooperation is not required in all forms of collective intentionality. I am not so sure. Searle points to cases where we collectively recognise a general practice and just go along with it, for example, using cash, speaking English, driving according to conventions of the highway-code. Because we just go along with it, suggests Searle, we are not appropriately described as cooperating as such. Once though we see these collective practices as properties of communities, facilitating community coordination, then I think we must indeed interpret our participation as a form of cooperation. When I stopped driving on the outside lane of the dual carriageway of the road leading into Cambridge I was precisely cooperating with all the others in managing the emergent pattern of traffic flow.
} 
I say 'in effect' because positions, positional powers/functions, and positioning are not Searle's language. Instead he advances a framework that instead employs the (apparently parallel) set of terms or expressions status, status function, and the assignment of function ${ }^{13}$. For Searle one of the most important applications of collective intentionality is precisely the collective assignment of function to people or objects. This is achieved by way of speech acts comprising, or taking the logical form of, Declarations. These in their turn require or presuppose a language cable of facilitating the creation of status function declarations, and most especially constitutive rules. Let me briefly elaborate.

According to Searle, "humans have the capacity to impose functions on objects and people where the objects and the people cannot perform the functions solely in virtue of their physical structure" (2010, p. 7). Rather the performance of the function "requires that there be a collectively recognized status that the person or object has, and it is only in virtue of that status that the person or object can perform the function in question", as already noted.

The required collective acceptance or recognition, an orientation that carries no necessary implication of approval, is a form of collective intentionality. For "the status functions to actually work, there must be collective acceptance or recognition of the object or person as having that status" $(2010$, p.6).

Somewhat confusingly, perhaps, Searle suggests that it is these status functions (as opposed to statuses) that carry deontic powers, meaning that they "carry rights, duties, obligations, requirements, permissions, authorizations, entitlements, etc." (2010, pp. 8-9). In any case, statuses and deontic powers are associated.

How do these statuses and status functions come about? According to Searle, they are created by speech acts of a type he calls Declarations, or at least those that take the same logical form. A Declaration is a form of speech act that serves to change reality to match the propositional content of the speech act, where, according to Searle, the reality in question is so changed just by representing it as being so. When, as an example, the British Queen declares that a new session of Parliament is open, or a judge declares that a court session is adjourned, then by those very acts of Declaration that which is declared becomes the case in fact. Similarly if someone declares 'I promise that' or 'I apologise for...' then in those very Declarations they are creating a promise and making an apology, etc.

Searle believes this is how money, corporations and all aspects of what he terms institutional reality, with the exception of language itself, are in fact created:

"One of the primary theoretical points of this book is to make a very strong claim. With the important exception of language itself, all of institutional reality, and therefore, in a sense, all of human civilization, is created by speech acts that have the same logical form as Declarations" (Searle, 2010, pp. 12-13).

\footnotetext{
${ }^{13}$ Though here and there Searle does slip into talk of positions. For example at one point he writes: "But to declare war, adjourn the meeting, or divorce, you need something more than that [a competent speaker of the language]: you need to be in a special position where an extra-linguistic convention gives you the power to create the corresponding institutional fact" (Searle, 2010, pp. 111-12)
} 


\section{Institutional reality}

Before going further it is important to note that Searle here uses the expression institutional reality, and cognate categories like institution, and institutional facts, in a manner that is both somewhat idiosyncratic (certainly the terms are not used in the traditional manner of expressing a feature of social reality that is recognised to be relatively enduring - see Lawson 2014a [2004]), and also reflecting of the evolution of his thinking. Let me briefly elaborate.

According to Searle, a status is, or can be, created by Declaration. Call the status Y. Let X be anything to which it is ascribed in context $C$. So by Declaration ' $X$ counts as $Y$ in $C$ '. For example, a particular room counts as a study in my house.

An institution for Searle is a set or system of constitutive rules having the form ' $\mathrm{X}$ counts as $\mathrm{Y}$ in C'. For example, such and such counts as a legal knight move in chess. Clearly Searle's constitutive rules take the same logical form as a simple Declaration. Searle in fact interprets these as 'standing declarations'. By this he means Declarations for which there is no need of a separate act of acceptance or recognition (that each X counts as a Y) because the recognition is already implicit in the acceptance of the rule.

Note that if we omit the "count as" phraseology and instead write such and such is a legal knight move in chess we are expressing a set of claims that Searle refers to as institutional facts. These sorts of facts, unlike other facts, termed 'brute facts' (the Moon takes an elliptical path around Earth; the average distance from Earth to the Moon is 384,400 km), are said to require institutions (sets of constitutive rules) in order to exist ${ }^{14}$.

Even so, the question remains as to why any reality created by Declaration is referred to as institutional, when it is evident that not all of it, even in Searle's reckoning, is constituted via standing declarations (sets of constitutive rules) specifically. The answer is that when Searle originally worked out his theory he held the view that in all cases where status functions carrying deontic powers are assigned they are so via constitutive rules. Hence he designated all of this reality to be institutional. Although in his later work Searle concludes that that there are other possibilities, and in particular that a simple Declaration can occur in the absence of any constitutive rules, Searle finds it convenient to persevere with his earlier terminology. Hence all reality that is said to be created by Declaration and involving deontic powers, and all facts thereby supported, are referred to as institutional. This usage thus expresses a reality not necessarily tied to constitutive rules.

So to take stock, the two conceptions of social ontology, though sharing much in common, do manifest apparent differences. The Cambridge project emphasises emergent social entities, and especially communities and their properties, and most especially positions, collective practices and associated deontic powers; the project associated with Berkeley, emphasises collective intentionality, status function declarations, and institutional facts.

\footnotetext{
${ }^{14}$ Searle thus writes: "Some facts exist independently of any human institution. I call these brute facts. But some facts require human institutions in order to exist at all. An example of a brute fact is the fact that the Earth is 93 million miles from the sun, and an example of an institutional fact is the fact that Barack Obama is President of the United States. Institutional facts are typically objective facts, but oddly enough, they are only facts by human agreement or acceptance. Such facts require institutions for their existence. Typically, institutional facts are facts that only exist within human institutions. And what exactly is a human institution? We have already seen an implicit answer to that, and I now want to make it explicit. An institution is a system of constitutive rules and such a system automatically creates the possibility of institutional facts. Thus the fact that Obama is President or the fact that I am a licensed driver or the fact that a chess match was won by a certain person and lost by a certain other person are all institutional facts because they exist within systems of constitutive rules" (2010, pp. 10-11).
} 
Are these differences reconcilable? It is certainly the case that the former Cambridge conception allows for collective intentionality, a codification of collective practices as rules and supports the generation of institutional facts; and it seems to me that an account that emphasises collective intentionality, status functions institutions and institutional facts equally presupposes an account such as I have outlined in terms of emergent totalities including communities and collective practices.

The latter, though, is not how Searle interprets matters. In particular, because he 1) interprets the linguistic element as somewhat more foundational for, certainly necessary to, the features of social reality that concern him, he in consequence 2) rejects all talk of social entities, or anyway social objects, presumably including thereby any notions of emergent social totalities, as at best unnecessary. In fact, he regards any talk of social objects, where meaningful as derivative of talk of institutional facts.

Let me, then, run through these two strands of Searle's thinking and supportive argumentation. I will indicate why I believe that the arguments made by Searle neither establish the necessity of linguistic representation of the sphere of reality that interests him, nor undermine the sort of social-entity, including community, based account I defend. Rather I believe the arguments made are suggestive of the inference that the two ontological conceptions being contrasted are ultimately not so different after all. I start with the question of the necessity of language to social deontology.

\section{The necessity of the linguistic?}

Why do I regard the linguistic aspect of social reality not to be foundational or necessary to all aspects of social reality that Searle designates institutional? As I say, I believe there is a practical dimension; my concern is that this is underplayed, if not mostly neglected, by the focus on the linguistic. To get to the nub of the issue, Searle, if I understand him correctly, supposes that it is impossible to have deontic powers without a developed language, whereas I think such powers are implicit in the collective practice, which though presupposing of intentionality and forms of representation, ultimately does not require any kind of developed language.

Let me be clear what I am not suggesting. It may well be that all of 'institutional reality' can be given a representation that has the same logical form as that which Searle terms a SF Declaration. I suspect too that (though remain open minded whether) any act that is undertaken intentionally to bring into being, or to shape, or to transform, a deontology may require language. Certainly, I believe that all forms of deontology depend on forms of representation. My concern, though, is something else. I take the view that deontology, and specifically any bound up with the collective practice, does not actually necessitate language; collective practices can emerge without it.

Notice that the issue here is not merely whether an explicit declaration is involved. Searle is quite flexible in his treatment of the idea of a speech act. If, to return to an earlier example, a queue, say, forms in a given direction at a food station in a rock concert, and every newcomer to the queue conforms, then a collective practice will have emerged without any actual Declaration being made or even any speech act uttered. However, Searle appears to think of such practices as created by thought processes of the same linguistic type as Declarations just 
because, or so Searle argues, it is in its being represented as existing that the queue exists. At least this is how I interpret Searle when he qualifies his position as follows:

"Not all of them [institutional-reality-creating speech acts] are, strictly speaking, Declarations, because sometimes we just linguistically treat or describe, or refer to, or talk about, or even think about an object in a way that creates a reality by representing that reality as created. These representations have the same double direction of fit as Declarations, but they are not strictly speaking Declarations because there is no Declarational speech act" (2010, p. 13)

In this case, as I say, I assume the speech act is merely a thought about the queue. Still it is not obvious to me that in this case the collective practice in question is created by any speech act whatever the supposed logical form; rather the linguistic representation may arise after the event, if required. All that is required it seems to me is a belief that a specific collective practice is in place. I am not sure that this in itself necessitates a fully developed language.

For Searle, though, there is little doubt that it is speech acts of some form that create institutional reality; that "institutional reality, and therefore, in a sense, all of human civilisation, is created by speech acts that have the same logical form as Declarations" (Searle, 2010, pp. 12-13).

So let me indicate why I associate a deontology with the collective practice, which though presupposing of intentionality and forms of representation, does not ultimately require any kind of developed language.

There are two aspects to this latter assessment. The first is that the collective practice carries, in the sense of manifesting or presupposing, a deontology. The second is that the collective practice does not necessitate language. In fact, I would go further and suggest that the emergence of language likely required, as a precondition, the existence of deontologycarrying collective practices.

The reason that I believe that the collective practice carries a deontology is that its acceptance or recognition implies not merely a belief about how to do things but a belief about how things ought to be done (by anyone wanting to be participant in the relevant community). The collective practice thus possesses a characteristic that Searle describes as a two way direction of fit (of intentional states and actual collective practice to each other).

The examples of driving and queuing already discussed do I think also support the notion that collective practices can and do emerge without language. However, this observation is unlikely to convince an opponent of this view. For as noted I agree with Searle that, in all cases where a deontology arises, representations of some form are also involved; and it is always open to the opponent of my view to suggest that in a community with language all representations are linguistically mediated.

So let me instead turn to the issue of whether collective practices that carry deontologies could have existed prior to language. Necessary conditions for this possibility, it seems to me, include intentional states such as desires and beliefs, collective intentionality, simple dispositions, along with an ability to cooperate, each of which Searle accepts as almost certainly being available to prelinguistic animals (e.g. 2010, p. 65, p.87). 
If such conditions indeed prevailed, it is easy enough to imagine of early hominids that where experimental cooperative practices are discovered to be advantageous in some way they might be repeated by the discoverers and imitated by others, perhaps even to a point where dispositions so to act are established. It is also easy to imagine how certain new sets of cooperative practices might link or fit with those already repeatedly followed, so that their success is linked to those already in place. It is equally easily imaginable that new arrivals on the scene including children come to believe that in the relevant context the practices in question are the done way, the natural or given way. In consequence, in seeking to fit in, to conform, to belong, they find reason to pursue goals in ways, or according to practices, they otherwise might not have been inclined to follow. In other words, it is imaginable how deontology could have emerged without language.

Because shared practices are never universal it is also easy to see how along with the emergence of specific shared practices that are regarded as the done way of proceeding a sort of group identity or association would come into being. That is, it seems likely that communities and coordination-facilitating collective practices emerged together.

For example, it is easy enough to imagine groups emerging around shared practices of obtaining and distributing food and water, of seeking protection from danger, of sheltering, of child care, disposal of the dead, and so on. With the development of such practices it is also easy to imagine the development of shared dispositions to treat collective practices as basic to community coordination, and so of believing that they are the proper or done ways of proceeding.

However, it is not just the case that it is easy to imagine how collective practices could have emerged prior to language (an activity that is inevitably overly speculative), it is difficult to imagine how language could have come into being without the prior existence of collective practices. In particular, it is difficult to imagine both how language could emerge outside of a community, and also how the sort of coordination required for any kind of community life in general, as well as for the emergence of language in particular, could be feasible and survive without deontology-carrying collective practices of some sort.

In particular, it is very likely the case that a necessary precondition for the emergence of any fully developed language is the prior practice of using simple symbols including sounds in communication. These would have signalled basics like danger, or food, etc. The point, though, is that in order that these function in the sense of communicating the intended meaning of the utterer, specific sounds would need regularly to be associated with the same referent (like 'danger'), with an effective obligation accepted by those involved not to vary the association. But it is difficult to see how this sort of relatively complex form of cooperative practice of associating symbols with features of reality in a collective manner could develop outside of small communities already coordinated by, and familiar with, rather simpler forms of (emergent) collective practice. In other words, if to repeat, linguistic practices appear to presuppose the existence of non-linguistically based deontology-carrying collective practices that are always required for community/group members' coordination.

If Searle rejects this assessment, and he does suggest over and again that any deontology per se necessitates language, his challenge, I think, is to indicate how language could have emerged without the prior existence of deontology-carrying collective practices. In truth, though, I find his account to be reasonably compatible with that just set out. 
Of course, given his emphasis on language as necessary to all institutional reality Searle has analytical problems or tasks specific to his own conception, and in particular that of showing that each Declaration itself, a form of institutional reality after all, does not require other Declarations, triggering an infinite regress. Searle of course is aware of this, and up to the challenge ${ }^{15}$.

The question that I am pursuing, though, is a different one. It is not specifically about how Declarations emerged without prior Declarations, but how any kind of language emerged. My question is in virtue of what does the sentence "Snow is white" mean that snow is white? Before any declaration is made, or linguistic operation can be performed to create some new institutional facts, how do we get to know the meaning of the statement "this piece of paper is cash"?

The term that Searle uses that is closest to my own notion of collective practice is convention. And turning to Searle's own account of the emergence of language one of the necessary conditions seems to be precisely a collective practice that Searle terms a 'meaning convention'. Let me say something about Searle's account of language.

For Searle one primary function of language is to communicate. And a feature fundamental to this is meaning. Searle distinguishes speaker meaning and conventional meaning.

Speaker meaning has two aspects and two conditions of satisfaction. The first is an intention to produce an utterance, for example 'it is raining'. This is satisfied if the intended utterance is in fact made. The second aspect is an intention to produce the utterance in conditions where the state of affairs the utterance is intended to represent are actually true; in this example in conditions in which it is actually raining. Alternatively put, the intention is to impose conditions of satisfaction on conditions of satisfaction.

Conventional meaning, in contrast, is a collectively or "socially recognised device, some repeatable device, the production of which can regularly be intended by speakers to convey the message" (p. 75). It is a repeatable device that can be used to convey speaker meaning, the latter being a token of the former type. In my terms it is a linguistic collective practice. Searle writes:

\footnotetext{
${ }^{15}$ As Searle observes:

"[...] all of institutional reality is created by linguistic representation. You do not always need actual words of existing languages, but you need some sorts of symbolic representation in order for the institutional fact to exist. As I noted before, there is, however, an interesting and crucial class of exceptions: linguistic phenomena themselves. Thus, the existence of a Declaration is itself an institutional fact and thus a status function. But does it itself require a further Declaration in order to exist? It does not. Indeed, if it did, we would have an infinite regress." (2010, p. 14)

So what is it about the Declaration that makes it a system of status functions that is exempt from the general requirement that all status functions are created by Status Function Declarations? Searle's answer is that the utterance of a phrase like "snow is white" has one function. It counts as a statement that means that the snow is white. However an utterance of the phrase "this piece of paper is cash" has two functions. Linguistically the utterance counts as a statement that just means that this piece of paper is cash. Non-linguistically, it counts as a declaration or a linguistic operation that constitutes this piece of paper as cash. In both cases, the semantic content is sufficient to render the utterance a statement. But the semantic content itself is not enough to make this piece of paper cash.

As Searle puts it:

"The meaning of the sentence "Snow is white" by itself is sufficient to guarantee that an appropriate utterance will constitute the making of a statement to the effect that snow is white. But the meaning of the sentence "Obama is President" by itself is in no way sufficient to guarantee that Obama is in fact President. In the case of the sentence, formulae of the form "X counts as $\mathrm{Y}$ in $\mathrm{C}$ " describe the constitution of meaning and not a separate linguistic operation that we perform. But, in the case of nonlinguistic institutional facts, constitutive rules of the form " $\mathrm{X}$ counts as $\mathrm{Y}$ in $\mathrm{C}$ " describe a linguistic operation that we perform by which we create new institutional facts, facts whose existence involves more than just the meaning of the sentences and utterances used to create them" (2010, pp. 14-15)
} 
"With the introduction of repeatable devices that can be used to convey speaker meaning on a regular and repeatable basis, we have introduced the notion of a linguistic convention and with it the notion of a standing word or sentence meaning. The conventional device for conveying speaker meaning now has a permanent sentence of its own. In describing this we have invoked the distinction between types and tokens" (2010, p. 75)

Searle lists various other necessary prerequisites or components of language, but it is his linguistic convention that concerns me here. Once Searle has introduced and explained all the various components he writes as follows (where the italics are added by myself):

"The animal has the intention both to impose conditions of satisfaction on conditions of satisfaction (and thus to create meaning) and to communicate those conditions of satisfaction (and thus, that meaning) to other animals. It does this according to conventional procedures. Those collectively accepted conventional procedures enable the hominids to create a type of commitment that is internal to the procedures but is not present without the collective procedures. There is no way I can say to someone, publically, intentionally, explicitly, "There is an animal coming towards us", without being publically committed to the truth of the proposition that there is an animal coming towards us, and that commitment is much stronger than the commitment to the corresponding belief by itself. [...] I am committed to sincerity in making it, and I can be held publically responsible if it turns out to be false.

So once we have an explicit language in which explicit speech acts can be performed according to the conventions of language, we already have a deontology" $(2010$, p. 82 , italics added by TL)

It is indeed the case that once we have a language we do already have a deontology. But I am suggesting that we have a deontology even before we have a language as one of the latter's preconditions. The excerpt from the foregoing passage that I have italicised does I believe get to the essence of it. Searle earlier in the text defines the notion of a commitment in terms both of 'an undertaking that is hard to reverse and [...] an obligation' (pp. 81-2). In the italicised passage Searle allows that commitments - and so a deontology - can both require and be internal to conventional procedure, or to what I am calling collective practice. The emergence of language seemingly thus presupposes a familiarity with collective practices. Clearly, on pain of circularity, Searle's notion of conventional procedure required for the communication of speaker meaning cannot be created by declaration involving speaker meaning.

Consider too a passage that Searle uses in summarising his account of language. After allowing that "We have to assume that they [early hominids] are capable of evolving procedures for representing states of affairs where the representations have speaker meaning" Searle writes of the procedures in question:

"These procedures, or at least some of them, become conventionalized, become generally accepted. What does that mean exactly? It means that given collective intentionality, if anyone engages in one of these procedures, then other members of the group have a right to expect that the procedures are being followed correctly. This, I take it, is the essential thing about conventions. Conventions are arbitrary, but once there are settled they give the participants a right to specific expectations" (Searle, 2010, p. 87)

This 'right' is a form of deontology and it is matched by the obligation of all other 'participants' to follow the procedure, a collective practice, correctly. 
Language, I am suggesting then, is in part built out of, and presupposes, the existence of the collective practice or 'conventional procedure'. Although, of course, I have no idea how matters actually evolved it is easy enough to imagine a community having collective practices prior to language, but not vice versa. I do not of course deny that very complex contemporary forms of social or 'institutional' reality involve a deontology that requires language as a necessary condition. I am just arguing that this is not so for all features of social reality that carry a deontology, that this social reality has a practical dimension, that it is in part linguistic but not linguistically constituted.

\section{Searle's refusal of all social objects or entities}

The feature identified at the outset above as appearing most manifestly to divide the two projects are differing commitments to notions of social entities or anyway to 'social objects'. Whilst I believe social entities or 'objects' are an essential feature of social reality, Searle has little time for any such idea and supposes that, at best, notions of social objects are derivative of institutional facts. We will see that these differences reflect those concerning the more fundamental ones concerning the role of language already covered.

To my knowledge the place where Searle expresses his views on 'social objects' and such like most systematically is in a published debate with Barry Smith (Searle, 2003; Smith, 2003). So here I consider Searle's stance in that discussion. The feature I do want to indicate is that Searle's critique there does not undermine the conception of social entities qua emergent totalities defended here. Nor is a case for the priority of institutional facts established.

So why and how does Searle resist talk of social entities or objects? Basically Searle's argument, at least as formulated in his debate with Smith, is that talk of social objects is misleading and likely to confuse. It implies that social objects form a separate class, along with kinds like water or iron, whereas Searle believes this cannot be the case.

According to Searle's conception, any object X can be interpreted as social only where, via a status function declaration, it comes to be counted as a social object (as a dollar bill or whatever). So $\mathrm{X}$ is, or is not, social only according to how we look at (or count) it.

Alternatively put, any such X can at one and the same time be both a non-social and a social object, with the implication that there can be no class of social objects that is distinct from the class of non-social objects. Searle concludes from this line of reasoning that any notion of social objects is likely to mislead:

"The notion of a social object seems to me at best misleading, because it suggests that there is a class of social objects as distinct from a class of non-social objects. But if you suppose that there are two classes of objects, social and non-social, you immediately get contradictions of the following sort: In my hand I hold an object. This one and the same object is both a piece of paper and a dollar bill. As a piece of paper it is a non-social object; as a dollar bill it is a social object. So which is it? The answer, of course, is that it is both. But to say that is to say that we do not have a separate class of objects that we can identify with the notion of social object. Rather, what we have to say is that something is a social object only under certain descriptions and not others, and then we are forced to ask the crucial question: What is it that these descriptions describe?" (2003, p. 302) 
Clearly Searle and I do not mean quite the same thing by the attribute of being social. For according to my conception any piece of paper is, even qua a bare piece of paper, a social object in that it has come into being through human interaction.

Even so, I still need to show that there is a distinct set or class of social objects, or structures etc., i.e., that the open sentence ' $\mathrm{X}$ is a social object' is extensional with respect to substitutability. But social objects, as I conceive them, do form a distinct class. An object X is social just if its existence does necessarily depend, in part at least, on human beings and their interactions. One and the same object X cannot both satisfy and not satisfy this criterion of the social.

The point is that according to the conception I defend, a social object comes into being via a process of emergence (including modification), not though being merely counted as social (as say in being counted as a dollar bill, or a passport) but in being formed as a totality out of pre-existing factors. In this process of emergence, the elements that become positioned as components may (or may not) themselves be social. But if not, and if they are not modified through the process of positioning, then the process of positioning per se (corresponding to Searle's 'counting as') does not itself render these objects social, or indeed a different kind of thing to that which they already were. In the process of being positioned, some pre-existing capacities of each element do thereby become interpreted as that element's set of system functions, and positional identities may be acquired. But there is no suggestion that any element so positioned itself becomes a new kind of stuff or whatever.

Thus, suppose some wild (or non-humanly modified) plants are arranged as components of a garden. Although the emergent totality (the garden) and the organising structure (the arrangement of plants, etc.) are social in that in part they depend necessarily on human practice, the plants do not thereby become social objects.

Or suppose I adapt Searle's example so that in place of pieces of paper our 'cash' consists in natural occurring but relatively rare forms of sea shell and/or bits of rare metal. By creating an accounting system in which these non-social objects are positioned as components, i.e., as cash, the latter would not become thereby social objects. However, the community as an emergent totality, structured in part by an accounting system in which these objects figure as components, would, qua totality, and along with its structure, definitely be social in nature; the community and its structure would constitute emergent features dependent necessarily on human interaction. But the shells and/or bits of metal remain non-social, albeit positioned and so serving as components of a social system. In so doing they do not change their nature and become a new kind of stuff, even if we can conceive of them as being attributed a novel social identity (expressing the novelty of their acquired positioning).

By similar reasoning, it follows that Searle's twenty dollar bill is neither both paper and notpaper, nor both a twenty dollar bill and not a twenty dollar bill. Either the object in question is positioned as a twenty dollar bill or it is not. It is never both. And wherever or however it is positioned there is always but one object.

So what precisely am I arguing? Let me summarise my position in the form of a response to a challenge issued by Searle. The challenge figures at the end of the following passage which summarises Searle's preference for thinking in terms of institutional facts rather than social objects: 
"In so far as we do have a coherent notion of social object, it is derived from the notion of social and institutional facts. Thus there is only one object which is both a piece of paper and a dollar bill, but the fact that it is a piece of paper is not the same fact that it is a dollar bill, even though they are both facts about one and the same object. A typical question from my analysis is: What is the relationship between the fact that this is a piece of paper and the fact that it is a dollar bill; how, so to speak, does humanity get from the facts about paper to the facts about dollar bills? I think you cannot ask or answer that question coherently if you start off with the idea that you are investigating the ontology of social objects" (Searle, 2003, pp. 302-3)

My own assessment to the contrary is that we can ask and answer the question coherently, and possibly only answer it sufficiently, if we start off with the idea that we are investigating the ontology of social objects. But providing the answer does require that we recognise that the various objects that concern us come to comprise components of different social systems. The different facts are implicitly about their serving as components of different totalities.

Searle mostly does not mention such systems but instead talks merely in terms of X counting as $\mathrm{Y}$ in $\mathrm{C}$. So we seem to have one object that is referred to as both as an $\mathrm{X}$ and as a $\mathrm{Y}$, and nothing to separate them beyond our 'counting as' practices (in C). But there $i$ s more. Or at least there is if my own conception is accepted. For an $\mathrm{X}$ becomes counted and so known as a $\mathrm{Y}$ only when it is materially/practically positioned as a component of a system. It is that material practical positioning that grounds or licenses the fact that $\mathrm{X}$ counts as $\mathrm{Y}$ in $\mathrm{C}$. That is how we get from facts about paper to the facts about dollar bills, via the material and practical positioning of the paper as a component in the community accounting system. Certainly, there is no problem here in starting off with the idea that we are investigating the ontology of social objects.

Moreover, it is often the case that any $\mathrm{X}$ we might consider is positioned as a component of various different systems simultaneously. For example, the computer in front of me is positioned as a component in a music system, a mailing system, a publishing system, a time keeping system, and so on ${ }^{16}$. In each system, a different capacity takes on the role of characteristic system function. And I can meaningfully refer to the computer as a media player, a mailing device, and so on. But there is nothing here that contradicts any requirement that there is but one object in front of me, or that contradicts any requirement that the object is not both a computer and not a computer, or both a component of a music system and not so, or whatever.

So, in short, like Searle I accept that we can often generate numerous institutional facts about a given $\mathrm{X}$. But I am suggesting that these relate to different positions that the $\mathrm{X}$ occupies; they are not claims that $\mathrm{X}$ has become different kinds of stuff. We can certainly attach to $\mathrm{X}$ various different positional identities, but still there is one object, that occupies many different positions. So the different facts generated express different but very real aspects of a very real social scenario. I see nothing in any of this that threatens a naturalistic account, or that justifies our giving up on the notion of a social object, or at least of emergent social entities and their structures. More positively, I am arguing that it is these positionings of $\mathrm{X}$ as

\footnotetext{
${ }^{16}$ Notice, too, though it is not an issue of relevance here, that just as the deontology associated with a position occupied by humans can be transformed (indeed individuals are often seeking to transform the powers to which they have access - see Lawson 2012, 2013a, 2013b, 2014b) so the functions associated with a give position occupied by objects can change. Thus where a computer is positioned as a component of a music system, the system function in question may be changed from providing music to listen to, to serving as a DJ tool, to serving as a means of sharing music/playlists with internet-connected friends, etc.
} 
a component of various different social entities - a matter of ontology of social objects or entities - that explains how we can get, and are justified in getting, from facts about $\mathrm{X}$ to facts about Y. This insight I think renders the account I defend more explanatory powerful than Searle's that seemingly cannot go beyond noting that different groups count various things differently

Similar sorts of considerations apply to the positioning of people, of course. Searle writes:

"Again, when I am alone in my room, that room contains at least the following "social objects": a citizen of the United States, an employee of the state of California, a licensed driver, and a taxpayer. So how many objects are in the room? There is exactly one: me." (2003, p. 302)

Yes and the one and same person is simultaneously positioned as components of different systems or communities. The latter are certainly social entities. But once more it is the different positionings, all real aspects of very real emergent social communities, that ground the generation of different facts about this single human being.

I am maintaining, then, that there is more to social existence or institutional reality than linguistic declarations or whatever. There is a material or practical dimension to social reality that grounds the institutional facts that can be generated. Searle's institutional facts essentially relate to features of the organising structures of social entities, and in particular positions and associated rights and obligations or social relations.

We can certainly agree with Searle that the various features of social reality thereby picked out are not like tables and chairs or solid objects, and in that sense they appear unusual ${ }^{17}$. But this insight does not, I think, compel us to reject their reality. Rather I maintain that in all these cases we are dealing with real aspects of a mind dependent, but not totally mind determined, social reality. Social structure in particular is continually reproduced and transformed through our individual practices in total, however aware or unaware, and indeed mistaken, we may be in our conceptions of all that is going on.

The point, in any case, is that Searle's arguments do not undermine the account of social entities defended here. Indeed I would suggest that the latter grounds Searle's conception. Certainly there is no obstacle to indicating how we can get from facts about $\mathrm{X}$ to those about Y by starting off with the idea that we are investigating the ontology of social objects. I am suggesting that institutional facts are facts not about isolated individuals but about individuals relationally organised as components of a totality, where that relational organisation of a totality is, like the latter, an emergent feature itself. As such, it seems to me, institutional facts are always derivative of things in the world. Certainly it is difficult to maintain that it is merely the other way round.

\footnotetext{
${ }^{17}$ Searle writes:

"Furthermore, many of the phenomena that are absolutely crucial to my analysis of institutional reality are not in any ordinary sense objects at all. Consider my obligation to pay money to you, which obligation I incurred when I made a promise to you last week. When I impose the status function on my utterance, one might, decide to construe the utterance as an object, at least in the sense that it was an event that occurred in space and time. But what kind of an object is an "obligation" that persists after the demise of its physical creation? And this is not an exceptional case on my account, because the ontology of institutional reality according to me amounts to sets of rights, obligations, duties, entitlements, honors, and deontic powers of various sorts. Smith thinks of all of these as "objects", but I believe that it is an obstacle to understanding their nature if you think of them as all objects in the sense in which chairs and tables are objects" (2003, p. 303)
} 


\section{Seeking to relatively evaluate the two conceptions}

I am suggesting then that on the points at which the two accounts seemingly diverge the emergentist account grounded in collective practice is the more explanatory powerful. Is there any way to discriminate further between the two conceptions by focussing on their contrasting implications? Is it possible to find ways in which they generate different conclusions that can be examined for their adequacy?

I think there may be. Being unconstrained by any notion that the formulation ' $\mathrm{X}$ counts as $\mathrm{Y}$ in $C^{\prime}$ ' is always grounded in practical matters of positioning objects as components of totalities, Searle has no reason to suppose even that his status functions, the Y terms, need actually always to be attached to some objects, the $\mathrm{X}$ terms. In recent years, indeed, Searle has come to accept that there are very significant cases where no such $X$ terms are required. Linguistic operations, it is held, can create 'freestanding Y terms'; a situation can arise where there is a status function but nothing, no $\mathrm{X}$ term, on which the latter is imposed.

From my own perspective in contrast, because institutional facts reflect a physical reality, there must be, and I believe there always is, an $X$ grounding any institutional claim (that $X$ counts as) Y. More specifically, there must always be an $\mathrm{X}$ actually or potentially positioned as a real component of a real emergent totality or system.

I think Searle is mistaken on this issue, and precisely because the social 'object' ontology underpinning his institutional facts is left overly implicit. In any case we have here an issue that can, as I say, likely help us discriminate further between the two conceptions. Certainly, if there are indeed freestanding Y terms, this would seem to suggest that the account I defend cannot be quite right. So it is to Searle's arguments in favour of freestanding Y terms that I now turn.

\section{Freestanding Y terms}

According to Searle there are apparently cases where status functions, forms of deontic powers, are regularly assigned that serve a purpose without requiring an object or person on which or upon whom the status function is imposed:

"Another interesting case arises when it turns out, in very sophisticated societies, that there are forms of the imposition of status functions, forms of deontic powers, that do not even require an object or person on whom the status function is imposed. Thus, what Barry Smith calls "freestanding Y terms" exist when a status function is created without there being an existing person or object who is created as the bearer of the status function" (2010, p. 20).

Let me quickly acknowledge that in my own framework too there are cases where it might be said that a position exists unoccupied. But these are rare and usually temporary at best. An example is where a position has but a single occupant at any given point in time, and the most recent incumbent dies or resigns or otherwise exits it, or a positioned artefact malfunctions and is removed, etc. But then, typically, the departing occupant is typically replaced as soon as is convenient, given the rules of positioning, or availability of alternatives, etc.

Certainly, according to my own conception, there is no sense in creating positions with associated powers or functions if there is no need or intention in the community in question to 
assign one or more (considered to be appropriate) occupants to the position. The aim always is to position an individual or object in such a manner that they bear the relevant powers or have capacities interpreted as functions, and thereby serve as functioning components of some overall system.

Of course Searle does recognise that any powers assigned need to be exercised, etc. But with Y positions thought to be unoccupied or Y terms said to be freestanding, he seeks to locate an agency of powers elsewhere. In so providing an account of where the agency lies I think that on occasion Searle too effectively presupposes the sort of social entity ontology I am defending, though if so it certainly remains unacknowledged. However, once or if such a conception is explicitly and systematically acknowledged, I believe that the case for supposing that any Y term might be freestanding collapses, as we shall see.

Let me then turn to Searle's argumentation. Searle mostly grounds his thesis by pointing to, and analysing, cases that he takes to be specific examples of freestanding $\mathrm{Y}$ terms. These are not trivial ones. They include the corporation, money and blind chess:

"The most obvious case of this is the creation of corporations. And indeed, the whole idea of the limited liability corporation is that there need not be any person or group of persons who is the corporation because those persons would have to accept the liability of the corporation if they were indeed identical with or constituted the corporation. But as they are not identical with the corporation, the corporation can exist, and continue to exist, even if it has no physical reality. Another case is the case of electronic money, where what exists are electronic representations of money; for example, magnetic traces on computer discs in banks. There need be no physical realization of the money in the form of currency or specie; all that exists physically is the magnetic traces on the computer disc. But these traces are representations of money, not money. Another obvious example is blindfold chess. The players have the powers of having the queen or the bishop or the rook, all of them deontic powers, but there is no physical object which is the queen or the bishop or the rook, only the representation of these in the standard chess notation."

Because Searle's case centres on the identification and analyses of these examples, I will focus on them too. My intention is to argue that none of the three supposed illustrations do, on close examination, render themselves amenable to being interpreted as examples of 'freestanding Y terms'. Let me then consider each in turn, along with Searle's analysis of who or what supposedly wields the powers if there is no X that counts as the Y. I start with the corporation.

\section{The corporation}

Contra Searle, the corporation does, I suggest, have a physical reality, an $\mathrm{X}$ with the status of a Y, an occupant of the position Corporation. The precise occupants of the position in question, I have elsewhere argued, are particular emergent communities (see e.g. Lawson 2012, 2013a, 2015b, 2015c). And these are very real and physical, including real human beings amongst their components.

For a community to be constituted as a corporation, or indeed as any kind of firm, it must be positioned, that is registered, in an appropriate (i.e., legalistic) manner. Specifically, in the UK anyway, a community has to be formally registered/positioned/accepted/assigned the status of sole trader, business partnership, limited company, or something similar, requiring, 
if positioning is to be successfully achieved, that the members are organised according to certain fairly general legalistic structures. But in the process the positioned object remains a community throughout.

When, however, a community is positioned (incorporated) specifically as a (limited) company (as opposed to a sole trader or ordinary business enterprise), something somewhat unusual happens: the community as a whole (i.e., a non-human entity) is positioned as a legal person (actually as a juridical person, with Juridical Person being a position within that of Legal Person, and containing within itself the position Limited Company [or Corporation]) On all this see Lawson 2015b, 2015c). This means that in law the community qua firm in question is interpreted as having certain rights and obligations normally associated only with natural persons. These rights/obligations include those of ownership, or suing and being sued etc. Of course the concept of ownership (if at all meaningful - again see Lawson 2015b, 2015 c) is itself a form of community position/status; owning is not a natural feature of human individuals any more than it is of communities as a whole. None of this, however, implies that some Y term (the corporation) is freestanding; all that follows is that the relevant position (the $\mathrm{Y}$ term) is occupied not by individual human beings qua isolated or unorganised individuals but by various whole communities; and rights that come with the position are associated with the latter.

Early examples of such legal persons were monasteries in ancient Rome. Although food and other items were donated to and/or gathered by the monks themselves, the monks were not allowed individually to own anything. So it was decided that the monastery, the community as a whole so positioned, was the owner (see Lawson, 2015b). Of course the relational structure organising the monastery will have included rules determining the allocation of food and so forth. Nothing though was freestanding. Just as the monastery qua community remained a real entity throughout so do other communities that become so incorporated.

Why does Searle suppose otherwise in the context of the modern corporation? To argue as I do it is necessary, of course, to accept the idea that the community as an emergent social entity. Searle does not take this path and in consequence interprets things very differently. Let me consider his specific arguments.

One reason Searle gives for treating the corporation as a freestanding Y term turns on an interpretation of limited liability. In the passage noted earlier Searle seems to suggest that the idea of the limited liability means there "need not be any person or group of persons who is the corporation because those persons would have to accept the liability of the corporation if they were indeed identical with or constituted the corporation." But the latter does not express the meaning of the term. When a firm is incorporated as a company/corporation it issues shares. Limited liability merely means that if a company gets into financial problems or other forms of trouble, its shareholders are not under the obligation to meet all the costs; in short their liability is limited. (Similarly if shareholders get into financial problems, the company cannot be expected to meet the cost over and above the shareholders holdings -though this is known as asset partitioning). There is nothing here that implies the corporation cannot be constituted as a group or better community of people without their accepting full liability. Moreover, there is once more nothing in any of this that warrants acceptance of the view that some Y term (or position) can be 'freestanding'. Searle though, concludes otherwise because, or so it seems to me, he is reluctant to embrace the idea of a real social emergent in the form of a community. 
A further reason Searle gives for suggesting that the corporation is appropriately interpreted as a freestanding Y term is that it is seemingly not created out of some pre-existing object. Specifically Searle writes:

"Notice that in the case of the corporation there was no preexisting object that was turned into a corporation [...] The law does not say that some pre-existing $\mathrm{X}$ becomes a corporation: rather it says that a corporation may be formed. It says that the performance of these written speech acts - 'executing and filing articles of incorporation' - counts as the creation of the corporation - 'the corporate existence begins upon the filing of the articles and continues perpetually'...” (2010, p. 98)

But the corporation is always formed out of something that pre-exists it. A community that comes to constitute (be positioned as) a corporation has to be legally registered (positioned). In order to be so registered it has to be assessed to be of an appropriate nature, including having an appropriate legal structure (see Lawson, 2015b). For this to be so the community must in effect already exist to be deemed appropriately enough structured to be legally registered. In fact very many communities that come to be incorporated are first registered as sole traders or ordinary business partnerships. Certainly this is so in the UK. That is, a community that has already been positioned, i.e., legally registered as (or assigned the status function of), a sole trader or an ordinary business partnership can through the process of incorporation be further positioned as a juridical and so legal person. Where a firm acquires corporation status from the outset, this merely means the entity in question, an emergent community, is effectively undergoing a double positioning in one move (see Lawson, 2015b). In other words, in creating a corporation an entity $\mathrm{X}$ is formed, that is a community, that becomes positioned in due course as a corporation. There is no freestanding $\mathrm{Y}$ term.

One final observation that Searle puts forward in support of the view that the corporation is a freestanding Y term, is that the corporation is often described as fictitious in some way. Thus although at times Searle appears to slip into the practice of referring to the corporation as an entity, he also qualifies this practice when he (also) refers to it, seemingly drawing on others, as a merely 'fictitious entity'. He further observes that limited liability companies are referred to as 'fictitious persons', suggesting that this is because they have no physical existence: He thus writes:

"[...] we need to specify not just that the function exists but that there is an entity $Y$, the corporation, that has the function, even though the entity is, as they say, a 'fictitious' entity. The point is that in such cases there is no independently existing $\mathrm{X}$. There is just the creation of an entity that has the Y status function, so the noun 'corporation,' carries both the name of an entity and the existence of the status function" (2010, p. 100)

"In the case of freestanding Y terms, there is no physical object or person to which the $\mathrm{Y}$ status function is assigned [...] Limited liability companies have no physical existence (that is why they are called 'fictitious persons')" (2010, p. 115)

Here Searle seems to make the (common) mistake of supposing that the frequent association of the term 'fictitious' with the corporation carries the meaning of an ontological fiction. Although there are many others, especially in economics and corporate governance, who also suppose this is how the terms fictitious and fiction are intended in the relevant context, such interpretations are based on misunderstanding. The terms in question are legal notions and in fact mean something entirely different. Let me briefly elaborate. 
In law and legal theory a 'legal fiction' is a term of art. It refers to an apparent claim about some situation that is in fact wilfully 'made up', assumed or created by the courts or some other regulatory body and treated as 'fact' in law, in order to enable a legal rule to be applied to the situation in question in a manner that was never intended when the rule in question was originally introduced ${ }^{18}$. Essentially it means some $\mathrm{X}$ is counted as legally some $\mathrm{Y}$ even though we all know that other than via legal declaration it is not a Y. Mostly, the term is used where the outcome is somewhat more specific in that some person or entity is allowed occupancy of a position in order to achieve access to a set of rights or obligations that were never intended for such a person or entity. Whatever the case, there is always an X. The whole point is to allow some $\mathrm{X}$ to be positioned/counted as a $\mathrm{Y}$. There is never a free standing Y-term

For example, adoption is a process whereby a child is interpreted as legally a son or daughter of a particular set of adults in order to grant both child and adults access to the rights and obligations of biological children and parents. The creation of the positions Adopted Child and Adoptive Parent is known as a legal fiction. But the individuals occupying these positions are not fictions.

A second example arises as a result of the fact that since an Act of Parliament of 1624 (with some modifications in an Act of 1707) MPs in the UK have been legally disallowed to resign from parliament, except in such cases as an MP accepts an office of profit under the crown. Resignations (which were once, but are no longer, considered undesirable) are in modern time effected after all, but via the creation of two legal fictions. Basically two offices of the crown are maintained -- the Crown Steward and Bailiff of the Three Chiltern Hundreds of Stoke, Desborough and Burnham, and the Crown Steward and Bailiff of the Manor of Northstead - which are only nominally remunerated, carry no duties, and reside in the formal gift of the Chancellor of the Exchequer, for which any MP wishing to resign applies and is positioned $^{19}$. In neither case is an individual so positioned a fiction.

In the case of the corporation the law grants that a particular entity be regarded as a legal person in order for it to access certain rights and obligations intended only for natural persons. The mechanism for this is the creation of the position (or status function) Legal Person, containing the nested positions of Natural Person and/or Juridical person, the latter further containing the position Corporation, with the incorporated community positioned in (or assigned the status function of) the latter. The reason for this particular legal fiction is precisely to allow the community as a whole to have certain rights of individuals. In all cases there is not a freestanding Y term. Indeed, if to repeat, the whole point of a legal fiction in

\footnotetext{
${ }^{18}$ Jeremy Bentham who opposed its widespread usage wrote of it that: "A fiction of law may be defined as a wilful falsehood, having for its object the stealing of legislative power, by and for hands which durst not, or could not, openly claim it; and, but for the delusion thus produced, could not exercise it" (quoted in C.K. Ogden, 1932, xviii).

${ }^{19}$ On occupying such a position the individual (who thereby resigns from parliament) usually holds the relevant office until it is again used to effect the resignation of an MP. The two positions noted above are used in this way alternately. When more than two MPs wish to resign at the same time, the resignations are interpreted as being not simultaneous but as spread throughout the day, each member holding one of the offices for a very short period, measured in hours or perhaps minutes. The device or procedure in question, an example of a legal fiction, was invented by John Pitt when he sought to vacate his seat of Wareham in order to stand for Dorchester. In May 1750 Pitt wrote to the then Prime Minister Henry Pelham notifying him that he had been invited to stand for Dorchester, and asking for "a new mark of his Majesty's favour" in order to change his seat. Pelham wrote to William Pitt (the elder) indicating that he would intervene with King George II in support, and on 17 January 1751 Pitt was appointed to the position of Steward of the Chiltern Hundreds, and was subsequently elected unopposed as member for Dorchester.
} 
The use of the term fiction in this context is certainly misleading and so not especially helpful, and many are misled. It does not mean that the subject is an ontological fiction; in fact its use denotes precisely the operation with which Searle is most concerned: to allow one thing to count as something else. But I repeat the emphasis is on the 'one thing', a person or entity, that gets to count as something else; the point of it is to allocate a position occupancy or a status function to an actually exiting person or object etc. that requires it. There is always a material referent of the X term, and a corporation is not after all a 'fictitious entity', it is only a fiction if (inappropriately) considered to be (positioned as) a natural (rather than a legal, and in particular a juridical) person.

A further unfortunate, or anyway additional misleading, use of terminology is that the position (status function) Juridical Person is also variously, if informally, known as Juristic or Artificial or Fictitious Person. Use of the latter term is merely to indicate that although positioned as a Legal person the entity in question is not positioned as a natural person. There is no suggestion thereby that any entity positioned as a juridical person is not a real entity. The corporation is such a real entity, and specifically a community. And although it is not (positioned as) a natural person it is positioned as a juridical and so legal person, allowing the community qua corporation access to various positional rights originally intended only for natural persons. In other words, in all such cases of positions created as 'legal fictions', there always is an occupant (bearer) involved; there are no systematically freestanding $\mathrm{Y}$ terms.

\section{Searle's attribution of the Y deontology}

I mentioned earlier that in the belief that $Y$ terms are freestanding, Searle must identify some agency to exercise the associated powers. Or as Searle puts it, if the Y term does not bottom out in an $\mathrm{X}$ term it must bottom out elsewhere. His proposal runs as follows:

"The freestanding Y terms do not bottom out in concrete objects, but they do bottom out in actual people who have the deontic powers in question. So there is no object or person which is the corporation, but there are the president, the board of directors, the stockholders, etc. and the deontic powers accrue to them. A corporation is just a placeholder for a set of actual power relationships among actual people. The same holds for electronic money and blindfold chess. The owner of the money and the possessor of the queen have the relevant powers" (2010, pp 21-2).

But this suggestion that the deontic powers of the corporation accrue to individuals is not entirely correct. When financial and other problems arise it can be held that no individual bears responsibility. This in part is how limited liability works. The corporation as a whole is found to be liable. Indeed, throughout out the history of the corporation this has been a source of criticism by its opponents, a feature that allows various harmful activities carried out through its members qua community components to go unpunished (see Lawson, 2015b, 2015c).

Notably, though, in seeking a solution to the problem of how the deontology associated with the corporation might be exercised, Searle accepts that individuals are positioned as directors, president, stockholders, etc., and that power relations connect them. He just does not take the extra step and acknowledge that these relations serve to organise or bind the positioned 
individuals in question as components of an emergent social system that is the corporation. However without this acknowledgement of a totality and its intended function (in this case the co-ordinated production of goods and services to be sold to others, in a way that is intended to be advantageous to [at least some of] the community members, with [at least some of] that advantage interpreted as 'profits') it is not clear why specifically positions like those of President, Director, Employee, etc., are formed (as opposed to very different ones) or why they interrelate in the manner they do. I do not disagree with Searle that "the whole point of the creation of institutional reality is to create and regulate power relationships between people" (Searle, 2010, p.106). However, it is essential to recognise that, especially where a totality is created by design, the sort of totality it is (hospital, school, army, public demonstration, academic workshop) has a bearing on the sorts of positions and power relations that will be involved.

Once, though, we take the extra and (I believe) essential step and acknowledge that the relations that Searle mentions serve to organise or bind the positioned individuals in question as components of an emergent social system that is the corporation we can reject the notion that there is any placeholder involved. The corporation qua community is no less a placeholder than is the University of California at Berkeley, or the Berkeley Social Ontology Group. The corporation is an organised emergent totality. And it is onto this community-qua firm, a very real, not a fictitious, entity, that the specific rights and obligations of incorporation are bestowed.

\section{Money}

I turn to Searle's second suggested example of a freestanding Y term, namely money, or rather electronic money. Let me recall that Searle's reasoning runs as follows:

"Another case is the case of electronic money, where what exists are electronic representations of money; for example, magnetic traces on computer discs in banks. There need be no physical realization of the money in the form of currency or specie; all that exists physically is the magnetic traces on the computer disc. But these traces are representations of money, not money" (2010, p. 20; emphasis in the original)

Elsewhere Searle writes:

"[.... money can exist without any physical realisation. The magnetic traces on computer disks in banks that record bank balances are not actual money, but they represent the amount of money you have in your account, which you are able to spend without incurring any indebtedness even though that money has no physical existence.” $(2010$, p. 115)

My interpretation of passages such as these is that Searle is presupposing that the usual sorts objects that constitute (are counted as) money are the specific pieces of paper and bits of metal that are more immediately counted respectively as notes and coins. These together count as money. They are what Searle refers to as physical realisations of money.

Of course, being concerned with institutional facts, Searle does not provide an account of the nature of money itself. More generally he does not provide any account of what an $\mathrm{X}$ is counting as when it counts as a Y. Whether or not the Y term is thought to be freestanding, it must always be the case that Searle interprets the Y term as basically a placeholder. Where, as is typical, there $i$ s an $\mathrm{X}$ that counts as $\mathrm{Y}$ then the various functions or powers are allocated 
to a relevant $\mathrm{X}$, of course, and the $\mathrm{Y}$ term treated as merely a name. Thus, in his earlier work, when Searle interpreted money essentially as notes and coins so that it did bottom out in pieces of paper and bits of metal, Searle still treated the word money as a placeholder:

"The word 'money' acts as a placeholder for the linguistic articulation of all these practices ['owning, or buying, selling, earning, paying for services, paying off debts, etc.']. To believe that something is money, one does not actually need the word 'money'. It is sufficient that one believes that the entities in question are means of exchange, repositories of value, payment for debts, salaries for services rendered, etc. [...]" $(1995$, p. 53)

I am not sure if Searle's assessment that magnetic traces and electronic devices are not money is grounded in a belief that the latter do not fulfil the noted functions or in the fact that they do not take the hitherto more familiar form of notes and coins. If they $d o$ fulfil these functions Searle should surely count them as money. Thus, I assume he is suggesting that they do not and are but representations of such objects as notes and coins, etc. that do supposedly fulfil the noted functions. Of course, if magnetic traces etc., do not fulfil the noted functions it is not clear why Searle should associate them with money at all. Whatever the interpretation, I believe that Searle's basic assessment of the functions of money is not quite right, and that this follows once more from failing to acknowledge money as a real component of an equally real totality. Let me briefly elaborate.

\section{The nature of money}

So what is money? Of course there are varying conceptions and debates about this that I cannot cover here without providing a full length (contentious) treatise on money. The only reasonable way to avoid a long discussion on the intricacies of the topic is boldly and starkly to state what I take it money to be, in terms of a conception I have defended elsewhere (Lawson, 2012).

A first point to make is that like the term 'firm', the term 'money' is a generic one with no legalistic or technical definition. Although we can be clear on the meanings of terms like sole trader, limited company, bank notes and coins, cheques, debit cards, etc., terms like firm and money are general categories encompassing various specific kinds.

So where do we start? If we wish the term to apply to features of all the geographically, historically and culturally differentiated communities that are typically described as having (had) money, then I suggest there is but one thing common to them all: an accounting system. Implicitly or explicitly the various communities have notions of exchange and/or reciprocity, and an intent and means of ensuring that the results of exchanges are maintained in some kind of balance. Even here there is a basic problem of terminology. Should we use money for the items of value that give rise to the need of an accounting system, or for the various devices introduced within all the various communities to facilitate any such system of accounting.

For historical reasons I prefer the term 'money' to refer to the former and I shall use the term 'monetary devices' or 'money markers' to designate the instruments of accounting. Admittedly Searle seems to use the term money for certain of these accounting devises, and specifically he seems to suppose real money takes the form of cash. These terminological differences should not get in the way of the argument though. For Searle's claim is that in the 
midst of all this are freestanding $\mathrm{Y}$ terms. My aim here is merely to demonstrate this is not the case.

Particular examples of modern monetary devices (Searle's 'money') are certainly notes and coins, or cash. These, as I say, are the devices Searle seems to have in mind as (items that count as) proper money. The central feature that I think Searle does not fully convey, however, and indeed is absent from most discussions of these devices, is that their primary or system function is, as with passports, identity cards, wedding rings, and documents of ownership, etc., to identify the holder of the device (here cash) as an occupant/holder of a particular community position/status with associated rights (associated with specific obligations of others positioned elsewhere). The rights and obligations in this instance take the form of credit-rights (internally related to the debt-obligations of the issuer of the cash).

In other words, monetary devices like cash are essentially IOUs. They serve the system function of being a marker and/or record of relations of credit and debt ${ }^{20}$. Needless to say, a very significant difference between the sorts of IOUs that might circulate amongst friends (or people who know each other and are familiar with each other's 'credit worthiness') and bank notes and such like, is that that the latter are state backed. Basically modern governments through central banks create a legal order whereby banks have the right to create IOU's of a sort that the government will accept as legal tender. This means they can be used by all members of the community as a device facilitating the use of bank debt for cancelling financial obligations entered into with third parties as well as (or especially) for the paying of taxes.

In short, through government legislation rights and obligations regarding repayments of debts that hold between the holder and issuer of debt are transformed respectively into 1) rights of the creditor (the cash holder) to use that government debt to cancel personal debts occurred in acquiring goods or that accrue as a tax payer, and 2) obligations of the issuer, ultimately the state, to ensure that conditions are maintained that allow the government debt to serve the latter intended functions.

Underpinning all this is a reality of bank and ultimately government debt. The issuer of the cash stands in a relation of debt to its holder. If an individual holder of this debt seeks to make a purchase of say a television in a shop, they enter in the first instance into a relation of debtor to the seller of the TV. However, because the purchaser holds government or bank

\footnotetext{
${ }^{20}$ Consider a scenario in which I shop at my local grocers but forget my wallet and the owner of the shop, recognising me, and believing me to be both trustworthy and having access to an income - literally that I am creditworthy- allows me to take my 'purchases' on credit (this is an event that has actually happened on more than one occasion). I could sign a piece of paper, and so create an IOU, recording my debt; the IOU would serve both to identify myself as the debtor (the person with the obligation) by my signature (say), as well as the creditor (the person with the right to expect payment), namely the grocer, through possession of the IOU. I am taking for granted here that a monetary/accounting system is accepted throughout the community involving an accepted unit of account, in terms of which debts are conventionally recorded (as of course is the case in the early twenty-first century UK).

If the baker next door to the grocer shares the same opinion of my trustworthiness and creditworthiness, the grocer could in principle use this credit with me to 'purchase' bread or whatever, transferring that credit (with me) to the baker to cancel the debt incurred by this purchase of bread, etc., and in addition pass on the IOU (perhaps endorsed by the grocer) to the baker so that the latter can be identified as the person now holding the credit.

It is important to recognise that it is the credit relation that has value and can be used to cancel other debts. It exists whether or not an IOU is created. If an IOU is created then it acts merely as an identifier; it is not per se the credit-debt (right-obligation) relationship itself. If the grocer or baker were to misplace the IOU I could still seek to fulfil my obligations if I remembered them; indeed there is a good chance we would all remember the nature of the credit-debt or right-obligation relation involved (and if the grocer, baker and I knew each other very well it is conceivable that the credit relation could even be repeatedly transferred between the three of us, with or without written IOUs, as often effectively happens within some families or between some friends).
} 
debt as identified by a monetary device such as cash, this bank debt (identified by the cash held) can be used immediately to cancel the debt incurred in buying the TV (through handing over the cash).

But notes and coins are but one monetary accounting device amongst others. That is, they constitute merely one set of devices for keeping tabs on credits and debits in the economy. Electronic accounting and forms of electronic money are different ones. They, like cash, provide ways of identifying where specific credit-rights and debit-obligations lie. And they are as real and functional as any other monetary devices, i.e., they are as much accounting devices, as the cash. They (like cheques and credit cards, etc.,) merely work differently.

The functions that Searle identifies as those of money are really those of government-backed bank debt in a capitalist economy. Assuming that the government via the central bank facilitates certain conditions, then this debt can be used as a store of value, means of exchange, and so on. However, the precise monetary devices that are employed in the facilitation of any of these functions of debt (by tracking where the debt relations lie) will be a matter of choice depending on the available technology of the time.

So I maintain that we do not have a freestanding Y term in the context of forms of monetary devices (Searle's money) either. Clearly we may not always be using notes and coins to identify and keep track of the various credit-debt relations of the modern community. The various electronic accounting mechanisms are merely modern devices to the same end; they are positioned as modern forms of monetary devices or as some say modern 'money'. Whatever we call them they are positioned material devices functioning to serve the community accounting tasks assigned to them.

Searle cedes to the claim that the $\mathrm{Y}$ term is freestanding, it seems to me, only because he does not start from an accounting system as a whole conceived as a major aspect of the organising relational structure of a modern community. Once though we do so start, and we recognise that money in the form of cash is essentially an accounting device, we can see that various accounting or monetary devices are feasible and indeed, under capitalism at least, are always in existence. We can also see that there is little ground to identify any as having priority, as being in some sense the real form of monetary device, or to consider others as mere representations. In all cases, material devices are required to keep track of debit-credit relations, for in all cases something recognisable is required to identify the holder of something that is far less so. In short, where there is money there will always be some sort of material accounting device.

We can also appreciate that Searle's suggested solution as to where the powers of electronic money 'bottom out' assuming the electronic money to be a freestanding Y term is erroneous as well as unnecessary. Searle's examples of money are all forms of (what I am calling) monetary or accounting devices. And these in all their forms are essentially material artefacts. And artefacts never bottom out in people (who somehow acquire their 'powers'). Any positioning of an artefact or material object (in a system), or assigning of a status to it, serves to render one of its causal capacities its system function. This is not about human positional powers. The system functions of monetary devices are to facilitate accounting within the community. The various devices work in different ways. The function of cash in particular is to identify its holder as someone standing in a relation of credit with whoever issued the cash. The functions of other devices depend on design and context. But people do not take on these 
functions themselves. In all cases a material object is positioned as a system component of an emergent entity that is a community.

\section{Blindfold chess}

The example of blindfolded chess seems the least convincing of Searle's illustrations. Searle suggests that in blindfold chess we have only representations of queens, bishops and rooks in 'standard chess notation'. But in the more traditional form of the game there is no intrinsic form of queen, bishop or rook, and so on. These are always but symbolic markers of a set of moves. These could in principle take the form of bits of paper with say WQ, WB, WR (with $\mathrm{W}$ for white, Q for Queen, etc.). The fact that in blindfold chess players maintain a mental model of the positions of the pieces, and that moves are communicated via a recognized chess notation, does not mean there is a freestanding Y term. There will still be mental symbols involved, with certain symbols positioned to function in ways that are isomorphic to the manner of functioning of those pieces which in more conventional chess we refer to as a white queen or black bishop, etc., along with indicators of the positions of each piece relative to that of all others. There are no freestanding Y terms; it is just that the $\mathrm{X}$ terms are symbols represented only in the mind.

So once more we do not need Searle's solution requiring that supposed deontological powers of the pieces bottom out in those of people. In any case, the possessor of the queen in chess does not herself or himself (normally) acquire the function of serving to identify and/or track a chess character with an associated set of moves. He or she may, qua a chess player, have the rights and obligations to physically or mentally 'make' certain moves. But with some marker, material or mental, being the object that is actually or mentally manipulated, there is in any case no freestanding $\mathrm{Y}$ term requiring a human to serve as a surrogate $\mathrm{X}$ term.

In all such illustrations, it is simply unwarranted to suggest that freestanding $\mathrm{Y}$ terms exist or are required. Once we examine the true nature of the suggested examples - the corporation, money and blind chess - we find in each case definite concrete objects expressed by Searle's $\mathrm{X}$ terms. The point though is that in cases like the corporation and money these objects can only be accurately understood once an ontology of emergent social totalities and structures is accepted. Ultimately, then, the cases collected under the head of freestanding Y terms support an account that grounds Searle's counting practices in the emergence of social totalities.

\section{Conclusion}

My purpose here has been to highlight apparent differences in two conceptions of social ontology, of how society is constituted, and to examine whether such contrasts are fundamentally incompatible. Because this is my goal, a form of contrast, I repeat that I have avoided the temptation (in a paper that in any case, given its aim, is inevitably on the long side) to refer to the myriad of contributions that have critically examined one or other of the competing conceptions in isolation. The one conception, that which I defend, focuses on emergent social entities, especially communities, and the ways and means by which community members, perhaps typically though sub-communities, come to position human individuals and objects in various ways and more generally generate collective practices. The other, advanced by Searle, focusses on the contribution of language, invoking the categories of collective intentionality, status function declarations, and institutions as sets of rules (or standing declarations), along with institutional facts. 
Whether or not the differences between the two conceptions highlighted are more apparent than real the different emphases taken do lead to the drawing of different implications. Specifically Searle gives linguistic operations a far more central role than I do, and in consequence Searle avoids almost entirely any talk of the emergent social entities that are fundamental to my own account.

Though seemingly quite significant I am not convinced, however, that the noted apparent basic differences or orientations are irreconcilable. Certainly, in emphasising the reality of emergent social totalities and their relational structures I do not at all oppose a need for a naturalistic account or wish to deny a constitutional role of language, dispense with the descriptions that Searle calls institutional facts, or notions of collective intentionality, etc. But I have argued that it is the former emergent features that ground institutional facts and render them correct or not, albeit constituting a reality that depends on us and our attitudes and beliefs but which does not reduce to them. Searle may be reluctant to accept this assessment, but even if it is correct I do not think it undermines Searle's conception so much as provides, as I say, a practical grounding for it. So at the end of it all I remain impressed primarily not by differences in the two contrasted conceptions of ontology, whatever their true extent, but by how much they appear, at some level or other, to hold in common.

\section{References}

Latsis, John, Clive Lawson and Nuno Martins (eds.) (2007) Contributions to Social Ontology, London and New York: Routledge

Lawson, Tony (1994) A Realist Theory for Economics, in Roger Backhouse, (ed.) New Directions in Economic Methodology, London and New York: Routledge, pp. 257-85.

Lawson, Tony (1997) Economics and Reality, London and New York: Routledge.

Lawson, Tony (2003) Reorienting Economics, London and New York: Routledge.

Lawson, Tony (2012) Ontology and the study of social reality: emergence, organisation, community, power, social relations, corporations, artefacts and money, Cambridge Journal of Economics, vol. 36, no. 2, 345-85.

Lawson, Tony (2013a) 'Emergence, morphogenesis, causal reduction and downward causation', in Margaret S. Archer (ed.), Social Morphogenesis, New York: Springer, pp. 61-84.

Lawson, Tony (2013b) 'Emergence and Social Causation', in John Greco and Ruth Groff (eds.), Powers and Capacities in Philosophy, London and New York: Routledge.

Lawson, Tony (2014a [2004]) 'What is an Institution?' in Stephen Pratten (ed.) (2014).

Lawson, Tony (2014b), "A Speeding up of the Rate of Social Change? Power, Technology, Resistance, Globalisation and the Good Society" in Margaret S. Archer (ed.), Late

Lawson Tony (2015a). The Nature and State of Modern Economics, London and New York: Routledge.

Lawson, Tony (2015b) 'The nature of the firm and peculiarities of the corporation', Cambridge Journal of Economics, 39, 1-32.

Lawson, Tony (2015c). 'The modern corporation: the site of a mechanism (of global social change) that is out of control?' forthcoming in Archer, M. S. (ed.), Social Morphogenesis: Generative Mechanisms Transforming the Social Order, New York, Springer

Ogden, C. Kay, (1932) Bentham's Theory of Fictions, London: Kegan Paul, Trench, Trubner $\&$ Co.

Pratten, Stephen (ed.) (2014) Social Ontology and Modern Economics, London and New York: Routledge. 
Sarkar, Sahotra, ed. (1996), Logical empiricism at its peak: Schlick, Carnap, and Neurath, New York: Garland Publishers, pp. 10-31)

Searle, John R. (1995). The Construction of Social Reality, London: Penguin Books

Searle, John R. (1997) "Replies to Critics of the Construction of Social Reality", History of the Human Sciences, Vol. 10, no. 4, pp 103-110

Searle, John R. (2003) 'The Construction of Social Reality: an exchange', (a debate with Barry Smith) American Journal of Economics and Sociology, vol. 62, no1, pp. 299-309.

Searle, John R. (2010) Making the Social World: The Structure of Human Civilization, Oxford: Oxford University Press.

Searle, John R. (2006) Social Ontology: Some basic principles, Anthropological Theory, 6(1):12-29

Smith, Barry (2003) 'The Construction of Social Reality: an exchange', (a debate with John Searle) American Journal of Economics and Sociology, vol. 62, no1, pp. 285-299. 